\title{
Abordagem Geocrítica d'A Grande Velocidade (Notas de Gare) de Guiomar Torrezão (1898)
}

\author{
Sara Pascoal \\ CEI - P. Porto e IELT - FCSH-UNL
}

Resumo: Este estudo pretende convocar uma leitura multifocal do relato de viagens "A grande velocidade (Notas de Gare)" da autora Guiomar Torrezão. Partindo de um levantamento toponímico e das principais características da paisagem para cartografar o espaço vivido que será posteriormente cruzado com o espaço ficcionado, o espaço forjado literariamente, pela rememoração de autores e convocação de textos fundadores do género. Esta leitura fará realçar aquilo que Edward Soja designa por espaço terceiro, um espaço onde “(...) everything comes together... subjectivity and objectivity, the abstract and the concrete, the real and the imagined, the knowable and the unimaginable, the repetitive and the differential, structure and agency, mind and body, consciousness and the unconscious, the disciplined and the transdisciplinary, everyday life and unending history." (Soja 1996: 56)

Palavras-chave: narrativa de viagem, espaço, abordagem geocrítica, geografia literária

Abstract: This article intends to undertake a multifocal interpretation of Guiomar Torrezão's travel narrative "A grande velocidade (Notas de Gare)". Based upon a quantitative survey of the place names mentioned and a qualitative study of the described landscape characteristics we mapped the living space (first space) intersected with the fictionalized space, to enhance what Edward Soja calls the third space, a space where " $(. .$. everything comes together... subjectivity and objectivity, the abstract and the concrete, the real and the imagined, the knowable and the unimaginable, the repetitive and the differential, structure and agency, mind and body, consciousness and the unconscious, the disciplined and the transdisciplinary, everyday life and unending history." (Soja 1996: 56)

Keywords: travel narrative, space, geocritical approach, literary geography 


\section{Introdução}

O Romantismo traz consigo a voga da viagem a Espanha. Se a imagem da Espanha (e de toda a Península Ibérica) que prevalece ao longo do século XVIII é bastante negativa, retrógrada e lúgubre, abrasada nas fogueiras dos autos de fé e no fanatismo da Santa Inquisição, com paisagens desoladas, estradas perigosas, hospedarias da má fama, alimentando a chamada "Lenda Negra", por oposição a uma França e ao Norte da Europa onde floresciam os ideais iluministas ${ }^{1}$, esta imagem vai evoluindo com o decorrer do século $\mathrm{XIX}^{2}$. As invasões napoleónicas e a Guerra Peninsular (1808-1814) conduziriam milhares de soldados a Espanha, contacto que permitiu rever alguns dos preconceitos e pôr em causa estereótipos. A resistência heroica dos povos peninsulares, e neste caso específico do povo espanhol, suscitou a admiração e o interesse do resto da Europa. Como afirma Elena Fernandez Herr, a par da Lenda Negra, perduraria uma Lenda Branca ou Dourada, bastante lisonjeadora ${ }^{3}$ :

L'Espagne a joui et souffert de deux légendes, celle que les Espagnols appellent "noire", et qui a fait couler beaucoup d'encre, et une autre que nous appellerons "blanche", ou même "dorée", qui les a beaucoup flatés. Les deux sont, en partie tout au moins, le produit des émotions que soulevèrent les rôles opposés de dominée et de dominatrice. La satisfaction que le monde gréco-latin (et plus tard les Arabes) éprouva a exploiter et à posséder l’Espagne engendra la seconde, tandis que le dépit, la jalousie, l'humiliation, engendrèrent la première, à partir, dans les deux cas, de faits réels plus ou moins défigurés. (Fernández Herr 1973: 21)

A preferência romântica pelo medievalismo, pelas ruínas, pelo exotismo e orientalismo maurófilo, fará da Espanha um destino da moda. Por conseguinte, e como afirma Vincent Clément "pour un romantique, le voyage en Espagne est un aboutissement" (Clément 1998). Raymond Foulché-Belbosc arrola mesmo cerca de 858 narrativas de viagem de estrangeiros à Península Ibérica, das quais 599 são a Espanha, 380 dedicadas à Andaluzia. Os viajantes franceses escreveram um terço destas narrativas, os britânicos, um quinto e os americanos, um sexto. Todas estas narrativas contribuíram de forma decisiva para moldar a imagem moderna da Espanha, entre as quais se encontram, como é óbvio, as 
que foram redigidas pelos vizinhos portugueses, que constituem o objeto deste nosso estudo.

A narrativa de viagens convoca, explícita e implicitamente, uma representação do espaço, dado que comporta uma descrição espacial dinâmica que se manifesta nas mudanças de lugares pelos quais os viajantes vão passando nas suas deslocações, desde um ponto de partida até ao ponto de chegada. Por outro lado, e como afirma Pierre Brunel, viajar é um ato de comparação: “(...) le voyageur est comparatiste, et le comparatiste est un voyageur"4; por conseguinte, o nosso estudo convoca uma perspetiva comparatista para o estudo do espaço na narrativa de viagens ${ }^{5}$.

A Europa Meridional, e a Espanha de forma muito especial, constituem os horizontes geográficos mais frequentados pelos escritores-viajantes portugueses oitocentistas, até porque, a Espanha é um território quase obrigatório de passagem para os outros países europeus. Espaço vivido, portanto, cuja delimitação de roteiros mais frequentes, se não mesmo estereotipados, não será despicienda para compreender a perceção e a vivência desse mesmo espaço. Por conseguinte, percorrer itinerários de viagem de alguns dos nossos escritores mais célebres do segundo quartel de Oitocentos é equacionar a perceção do espaço da vizinha Espanha, mas igualmente "o conjunto de ideias sobre o estrangeiro tomadas num processo de literarização, mas também de socialização" (Pageaux 1994: 60). A viagem real, pela paisagem real, física e humana, não deixa de configurar uma viagem imaginada, um espaço ficcionado, pela rememoração de leituras, de mitologias de "miragens", normalmente de matriz francesa.

De facto, a Literatura de viagens recolhe o testemunho de todos os textos congéneres ou fundadores do género. 0 texto de viagens é filtrado pela realidade e pela biblioteca, provocando aquilo a que Christine Montalbetti chama "le risque de la redite" (Montalbetti 1998). Este efeito de "boule de neige", nas palavras de Pierre Brunel, é consubstancial ao género e parece constituir a forma do novo texto se legitimar, num processo remissivo para um saber cultural e livresco, partilhado pelo autor e pelo público-leitor:

La littérature de voyage fait en quelque sorte boule de neige. Non seulement les ouvrages précédents 
peuvent servir de guide au voyageur (Goethe utilise Volkmann, et Sthendal Lalande), mais encore le récit de voyage nouveau s'enrichit de leur substance. Pour l'érudit, l'invitation au voyage se transforme alors en sollicitation d’une archéologie livresque. (Brunel 1986: 8)

O escopo deste artigo será, pois, tentar compreender a reconstrução do espaço espanhol a partir da narrativa de viagem A Grande Velocidade (Notas de Gare) de Guiomar Torrezão. Ler e cartografar os espaços vividos destacará, por entre a plurissignificatividade do texto literário, o itinerário da mulher-escritora, o roteiro de uma geografia vivida e posteriormente ficcionada, a identidade nacional construída pela relação com o espaço, a paisagem, os ambientes frequentados e os segredos dos lugares inventivos, artisticamente construídos, que se cristalizarão em imagens pertinazes e estereotipadas que perdurarão até aos nossos dias, sob a forma de imagens turísticas.

Em síntese, a leitura desta narrativa de viagens, que se pretende multifocal, questionando e investigando a relação entre a abordagem do espaço real, o espaço vivido e o espaço ficcionado, que literariamente forjam em contacto com os espaços dos outros viajantes que leram e frequentaram, parece-nos fazer sobrepujar aquilo que Edward Soja designa por thirdspace. Neste terceiro espaço, como nos explica o autor americano, “(...) everything comes together... subjectivity and objectivity, the abstract and the concrete, the real and the imagined, the knowable and the unimaginable, the repetitive and the differential, structure and agency, mind and body, consciousness and the unconscious, the disciplined and the transdisciplinary, everyday life and unending history." (Soja 1996: 56) E define thirdspace como "(...) an-other way of understanding and acting to change the spatiality of human life, a distinct mode of critical spatial awareness that is appropriate to the new scope and significance being brought about in the rebalanced trialectics of spatiality-historicality-sociality"(Soja 1996: 57).

Esse thirdspace, que queremos destacar com a nossa análise, é aquele de cuja memória somos herdeiros, que foi propalado e enraizado na nossa matriz cultural e social, conformando-se na identidade nacional. A presente dissertação pretende discutir e evidenciar o papel desempenhado pelos viajantes portugueses da segunda metade de 
Oitocentos e pelos seus textos na construção identitária espanhola e, por conseguinte, na definição da identidade portuguesa ${ }^{6}$.

Para tal, utilizou-se uma metodologia que consistiu na análise desconstrutivista do discurso, elaborando para o efeito tabelas onde se procedeu a uma metódica reconstituição quantitativa e qualitativa dos topónimos referidos, que se comparou com uma arqueologia cuidadosa dos principais elementos da paisagem, cruzando-se esta informação simultaneamente com as referências literárias que pudemos isolar. Foi aplicada uma matriz de análise a partir da qual foram extraídas as seguintes informações: datação da viagem, autor, título da obra, data e local da publicação, editora. Nesta trama de análise, procedemos igualmente ao levantamento dos topónimos referidos pelos autores, para reconstituir os itinerários percorridos, bem como o tempo da viagem e de estada. Essas tabelas contemplam ainda a rigorosa notação das fontes literárias, direta ou indiretamente citadas, e que se conformam naquilo a que designámos por espaço ficcionado.

Esta análise e o levantamento a que procedemos permitiu-nos elaborar a cartografia temática que muito complementou este estudo. A viagem pela paisagem humana e real será, por conseguinte, alvo da reconstituição através destes mapas que nos permitem recuperar os espaços percorridos e descritos por Guiomar Torrezão.

Concomitantemente, às reflexões e às impressões que a autora recolhe no seu relato, e que se baseiam numa observação precisa e atenta da realidade, encontramos também referências literárias e um conjunto de ideias literalizadas, testemunhando uma visão percetiva do espaço vivido, mas também do espaço rememorado. Foi esta visão que tentámos reproduzir, a partir da comparação com outras narrativas de viagens de autores estrangeiros.

0 relato de viagens que selecionámos para esta abordagem geocrítica foi selecionado pela excecionalidade da sua autoria. Efetivamente é o único relato de viagens a Espanha da segunda metade de Oitocentos assinado por uma mulher.

N. ${ }^{3} 38-6 / 2018$ | 271-293 - ISSN 2183-2242 | http:/dx.doi.org/10.21747/21832242/litcomp38a15 


\section{A autora: Guiomar Torrezão}

Guiomar Torrezão, faz parte de um pequeno núcleo de mulheres que se consideram pioneiras das Letras em Portugal, a par de nomes célebres como a Marquesa de Alorna, Maria Amália Vaz de Carvalho, Ana Plácido ou Carolina Michaëlis de Vasconcelos, mas também de outros menos famosos dado a volatilidade do suporte em que nos deixaram os seus escritos, a imprensa periódica. Referimo-nos, por exemplo, a Branca de Carvalho, Mariana Angélica de Andrade, Maria José da Silva Canuto, Amélia Janny, Adelina Lopes Vieira, Antónia Pusich, Catarina de Andrada, Francisca Wood, entre tantas outras que não cabem nos limites espartilhados da nossa abordagem ${ }^{7}$.

Guiomar Delphina de Noronha Torrezão nasceu em Lisboa, em 26 de novembro de 1844, e morreu em 22 de outubro de 1898, na mesma cidade, filha de José Joaquim de Noronha Torrezão e de Maria do Carmo Pinto de Noronha Torrezão. Oriunda de uma família burguesa, desde cedo teve que prover à sua subsistência, dando lições de instrução primária e de francês, ao mesmo tempo que se iniciava na escrita, com notório sucesso. Guiomar Torrezão trabalhava não apenas por gosto, mas essencialmente por necessidade, pois o pai falecera cedo deixando a família (Guiomar, a mãe e mais uma única irmã) em precária situação económica. Fialho d'Almeida narra-nos os sacrifícios da sua vida desta forma:

Guiomar Torresão não tinha pai nem irmãos que exigissem contas aos desrespeitadores eméritos das mulheres sós; e não tendo constituído família, nem tendo fortuna própria, achou-se na condição de ter que ganhar ela mesma o seu prato e os seus vestidos, escrevendo para jornais todos os dias - isto é, cosendo à pena, em vez de coser à máquina, e não tirando deste esgotante martírio sequer talvez o que as pobres costureiras auferem nos armazéns onde trabalham. Todos sabem o que seja entre nós a chamada colaboração paga dos editores e dos jornais. (d'Almeida 1923: 189)

Apesar das adversidades, a sua inteligência e engenho permitiram-lhe cumprir um destino relevante como mulher e como escritora. Vivendo numa sociedade conservadora e tradicional, Guiomar de Noronha Torrezão foi vítima, como tantas outras mulheres, de críticas acerbas e ataques violentos. As mulheres escritoras eram designadas 
pejorativamente de bas bleu, termo aplicado "à mulher autora, denominação de toada pejorativa, a revelar a atitude de sarcasmo de que a mulher escritora é objeto no século XIX, mulher que é vista como ridícula, sabichona, pretensiosa ou mesmo de moral duvidosa."8

Guiomar Torrezão foi das mais versáteis escritoras do panorama literário do Portugal de Oitocentos, dedicando-se à poesia, ao drama, à ficção, mas também ao ensaio. Estreou-se, porém, com o romance Uma Alma de Mulher, publicado em folhetim, no jornal feminista $A$ Voz Feminina, em 1868. Em 1872, publica um livro de novelas e contos, Rosas Pálidas, ao qual se seguiu, dois anos mais tarde, o romance histórico A Família Albergaria. Em 1874, edita Meteoros, um livro de contos e crónicas e, em 1881, publica No Teatro e na Sala, obra com o prefácio de Camilo Castelo Branco, e ainda os livros de contos e estudos literários Idílio à Inglesa (1886), As Batalhas da Vida (1892). Como dramaturga, publicou Educação Moderna, comédia em 3 atos (1884) e também Dois Garotos, um drama em 5 atos (1879) e O Fraco da Baronesa, comédia em 1 ato (1878). Escreveu os romances Uma Alma de Mulher (1869) e Henriqueta (1890), entre outros.

Colaborou em diversas revistas, primeiramente com o pseudónimo Delfim de Noronha, mas depois assumindo a sua verdadeira identidade. Colaborou igualmente em vários jornais, como o Diário de Notícias, Gazeta Setubalense, Tribuna Popular, Crónica dos Teatros, etc. Mas foi como diretora da revista A Voz feminina que se destacou, encetando uma verdadeira batalha contra a falta de instrução feminina, tendo intuído muito precocemente que só a libertação da ignorância permitiria a independência feminina.

Fialho d'Almeida assinou o seu obituário, descrevendo-a desta forma: “ (...) grandemente talhada, forte e dum carácter autónomo d'onde sahem as iniciativas fecundas que individualizam para ser verdadeiramente alguém, ela só teve um obstáculo, o meio onde apareceu e se fez gente, em Portugal. Pois em Londres, em Paris, no Brasil, etc., teria sido ilustre. Mas em Lisboa, quase a quiseram tornar cómica." ${ }^{9}$

\section{0 Espaço vivido}

O relato do itinerário de Guiomar Torrezão a Madrid, editado no Porto, pela Livraria Portuense, em 1898, reúne a viagem efetuada pela autora a Madrid e a Paris. A primeira 
parte deste relato tem por objeto a deslocação da cronista social à capital espanhola, para fazer a cobertura, para o jornal Diario Ilustrado, do casamento da irmã do Rei de Espanha, Afonso XII, a infanta D. Paz, com o Príncipe D. Luís da Baviera, a 2 de Abril de 1883. Apesar de ser este o móbil da sua viagem, a verdade é que a narrativa é escrita anos mais tarde, uma vez que Guiomar Torrezão dá conta do desaparecimento de figuras como o seu anfitrião, D. Luis de Rute e do próprio Afonso XII.

A viagem em comboio inicia-se a 30 de março de 1883, às 5 da tarde, na gare de Santa Apolónia e demora cerca de 23 horas. Guiomar Torrezão irá utilizar a ligação ferroviária portuguesa a Madrid por Cáceres, Plasencia e Talavera de la Reina. Mais tarde apanha o Sud Express para efetuar o trajeto até Paris e, depois de passar cerca de 15 dias na capital espanhola, continua a sua viagem até à Cidade-Luz.

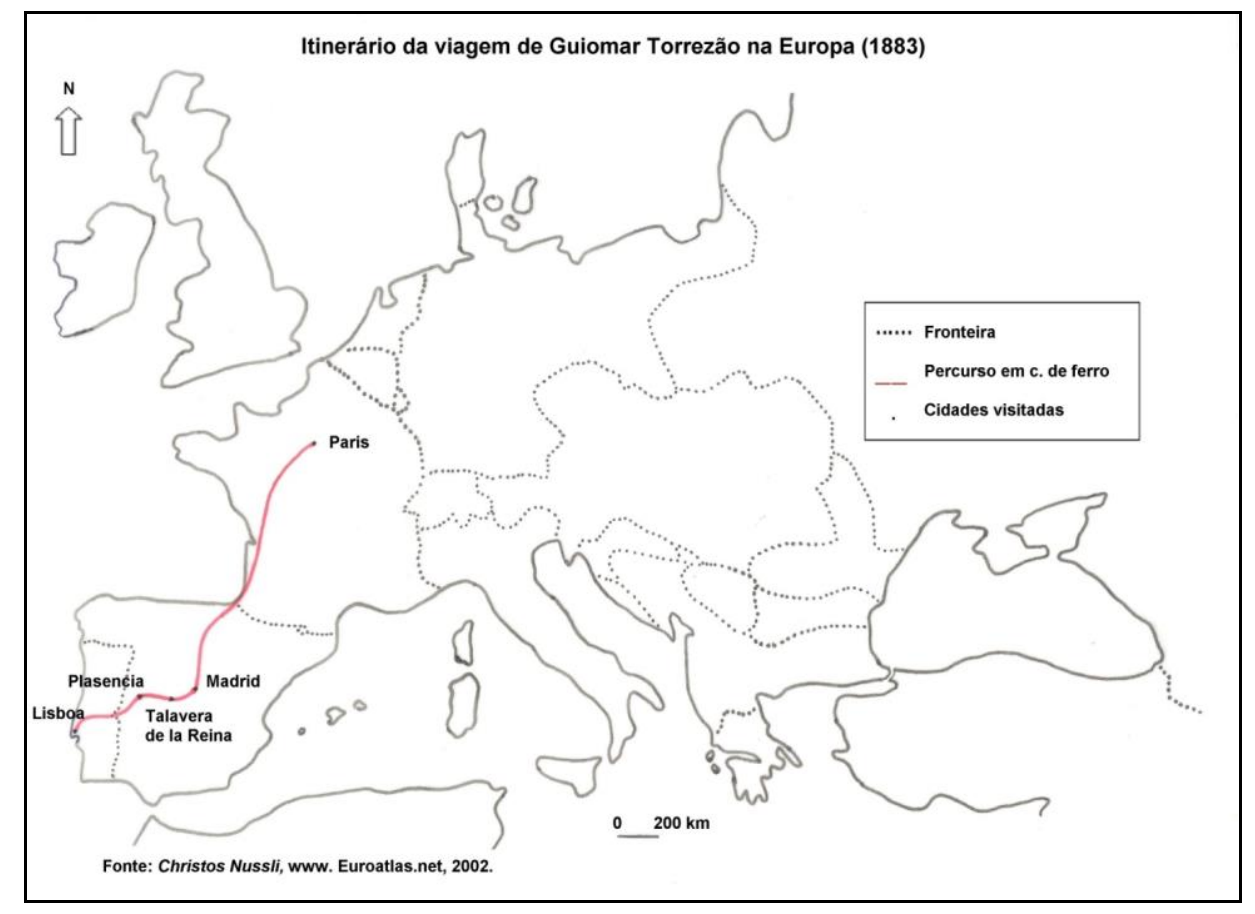

Fig. 1 - Itinerário da viagem da Guiomar Torrezão na Europa (1883)

Guiomar Torrezão assinala a passagem por cada povoação espanhola com rigor, arrolando topónimos de estações e apeadeiros, como quem escreve com os olhos postos num mapa, mas que de facto devem apenas provir da memória auditiva fonética do seu 
anúncio em cada estação, dadas as alterações que podemos verificar: "Mirabel, Plasencia, Bazagona, Lacalzada, Alcanizas, Calera, Valavera, Talavera de la Reina, Torrijos, Vilamiel, Bargas, Illescas, Griñon, Fuenlatrada, Leganeo e muitas outras.” (Torrezão 1898: 12). De facto, há algumas alterações como Fuenlatrada por Fuenlabrada, Leganeo por Leganés, Calera por Caleray ou Valavera por Talavera.

Durante a viagem, a escritora realça a monotonia da paisagem, pela sua aridez, onde só a breves momentos se consegue vislumbrar alguma "vegetação anémica". A valoração da paisagem é novamente de cariz romântico, com nítida preferência pela vegetação, pelas árvores, montanhas e serras, das ruínas de monumentos. Por fim, avista ao longe Madrid. A descrição da capital espanhola deixa transparecer o fascínio pela: "pompa gloriosa das suas edificações elegantíssimas, coroadas ao fundo pelo diadema das serras de Guadarrama", uma metáfora muito ao gosto feminino.

Em Madrid, Guiomar Torrezão aloja-se na casa de Luís de Rute, "subsecretario de la gobernacion", casado com a célebre e polémica Princesa Ratazzi, cujo palácio se situava na Calle Montalban, rua privilegiada do centro Madrid, onde habitava a alta aristocracia, perto do Buen Retiro e do Paseo del Prado.

Se é verdade que os livros de viagem que compulsámos privilegiam de forma nítida os espaços aristocráticos, de todos eles o de Guiomar Torrezão é aquele que os frequenta de forma mais evidente, assumindo a autora um papel óbvio de cronista social da aristocracia espanhola.É que, para além do facto de ser a única a alojar -se numa casa particular, partilha os mesmos espaços frequentados pela Princesa Ratazzi e pelo seu marido, oferecendo-nos um quadro muito completo da alta sociedade madrilena, quer da família real, quer da nobreza e da classe parlamentar com quem tem contacto direto.

Os itinerários circunscrevem-se, por conseguinte, aos espaços frequentados pela alta aristocracia, num eixo que tem por ponto de partida o Palácio Montalban. Aí, usufrui de todas as comodidades e regalias concedidas ao subsecretario de la gobernacion, nomeadamente, "uma elegante victoria dos donos da casa, tirada por dois sober bos cavalos; o criado de tabua com a libré de Sagasta (...) que pertence aos lacaios de D. Luiz de Rute”; o 
palácio Montalban é ainda guardado por “quatro guardas da gobernacion (...) que estão sempre postados à porta do palácio."

Os limites do espaço madrileno percorrido por Guiomar Torrezão circunscrevem-se ao eixo Plaza del Oriente - Retiro, passando pela Puerta del Sol. A estratégia escolhida na descrição dos espaços pode ser isolada em dois grandes paradigmas. Guiomar Torrezão oferece-nos, em primeiro lugar, uma visão de conjunto da cidade para, posteriormente, nos guiar pelos itinerários percorridos, o que se plasma numa visão fragmentária do espaço. Esta visão de conjunto, confidencia-nos a autora, é também ela parcelar e pouco nítida, mas poderá sintetizar-se numa expressão de deslumbramento:

Eis-me em Madrid, que vi apenas de relance, em uma visão instantânea e alagada em luz, mas que se impõe desde já ao meu espirito pela sua intensa vida, pelo seu ar de festa, pela sua risonha physionomia, eminentemente peninsular, pelas suas calles cheias de sol e de movimento, onde passa uma população buliçosa, exuberante de seiva, gesto rápido, passo leve (...). (Torrezão 1898: 10)

Mas esta visão de conjunto, logo à chegada a Madrid, rapidamente dará lugar a uma descrição dos espaços centrada nos trajetos percorridos. Num desses primeiros percursos, entre os numerosos eventos sociais a que assiste, descreve-nos a colocação da primeira pedra da Catedral de Almudena, por Afonso XII, no dia 4 de abril de 1883. 0 trajeto descrito parte, portanto, da calle Montalban, dirigindo-se para Oeste, passando pela Calle Mayor, até à Plaza del Oriente. No regresso, em direção ao Buen Retiro, Guiomar Torrezão empreende o caminho pela Puerta del Sol, colocando-a no centro nuclear da cidade de Madrid: "Imagine-se uma praça desafogada e ampla, onde afluem as oito principaes ruas de Madrid: Calle Arenal, Calle de Alcalá, Montera, Carmen, Carretas, Carrera de S. Geronimo e Mayor."

Puerta del Sol, para além do coração da cidade, é um espaço frequentado privilegiadamente pelo povo. Aí se sente "a exhibição da industria, a palpitação febril de uma capital pequena em extensão, enorme pela sua população numerosíssima." Madrid, no fim do século, continua a ser descrita pelos nossos viajantes como uma capital pequena, mas cuja população sofreu um acréscimo exponencial nos últimos anos. Para dar conta desta realidade, na descrição da Puerta del Sol, a figura retórica preferencialmente utilizada 
é a enumeração dos diversos tipos de edifícios, “lojas de modas, luvarias, livrarias, cafés, fondas, restaurantes, sobressaindo a fonda de Paris, e todas as industrias anunciadas em grandes letras doiradas", mas igualmente a sinestesia, na descrição das cores, movimentos e texturas da praça e da população que nela se encontra:

(...) ao centro, um tanque enorme, d'onde a agua irrompe em jorros, descrevendo no ar florescências de crystal retintas das cores do espectro solar e caindo em chuva prismática, modrendo a face liquida e calma da ampla bacia e repuxando em uma espécie de catadupa incendiada pelo sol. (Torrezão 1898: 22)

Em contrapartida, no outro extremo deste eixo, e passando por estas ruas, encontra se o Buen Retiro. Puerta del Sol e Retiro são, segundo a autora, “dois quadros que se chocam sem se confundirem." 0 Retiro é o espaço reservado à alta aristocracia, "à alta vida, a alta goma, a requintada opulência mundana da sociedade elegante." Ao contrário dos restantes viajantes e livros de viagem compulsados, a descrição do Buen Retiro é mais valorizada, em detrimento da que é realizada para a Puerta del Sol.

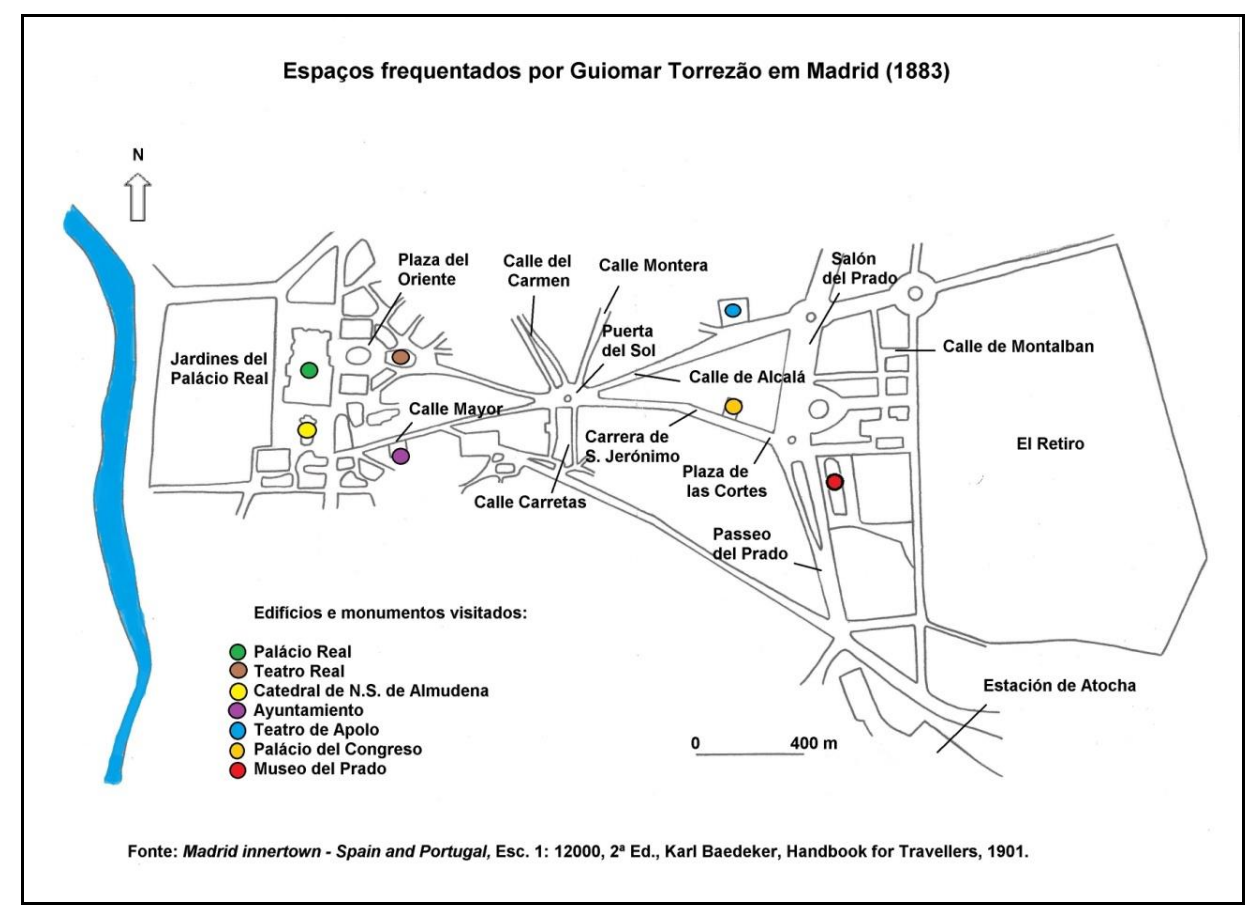

Fig. 2 - Espaços frequentados por Guiomar Torrezão em Madrid (1883) 
A estratégia retórica escolhida por Guiomar Torrezão para descrever o espaço do Buen Retiro é a comparação com os espaços que os leitores portugueses reconhecem, nomeadamente Lisboa e Paris. E Guiomar Torrezão assegura-nos não haver "nada em Lisboa que se assemelhe ao Buen Retiro, cuja extraordinária animação e aspecto característico excedem por vezes segundo o insuspeito testemunho de uma parisiense, o próprio Bois de Boulogne."

Entre as quatro e as seis da tarde, o Buen Retiro é o espaço de eleição da alta aristocracia e Guiomar Torrezão recorre novamente á enumeração, para ilustrar o luxo e a pompa dos veículos que aí circulam: "carruagens com librés vistosas e pitorescas, coupés, phaetons, tilburys, victorias, landaus"; "desde o lago até à extrema linha do passeio, transitam exclusivamente as carruagens da família real, ministros e corpo diplomático."

Por diversas ocasiões e a todos os ensejos, Guiomar Torrezão faz questão de sublinhar que a sua condição de hóspede da Princesa Ratazzi e de D. Luiz de Rute lhe dá acesso privilegiado aos espaços reservados à alta aristocracia, podendo assim passear -se no Buen Retiro ao lado da família real, que nos descreve com precisão.

Para além deste eixo Puerta del Sol - Buen Retiro, os restantes espaços frequentados pela narrativa da autora são essencialmente espaços interiores. A Madrid aristocrática da década de oitenta é palco privilegiado de crescentes distrações e a nossa viajante, convidada em casa da Princesa Ratazzi, entregar-se-á, tal com a sua anfitriã, à intensa vida social da capital espanhola. Assim sendo, descreve-nos as variadíssimas idas ao Teatro, frequentando desde o Teatro Real ao Teatro Apolo ou ainda o da Zarzuela. Depois do jantar, a partir das 10 horas da noite, a alta sociedade madrilena levanta-se "da meza para tomar logar nas carruagens que a conduzem ao teatro", hábito que Guiomar Torrezão diz ter acompanhado, "com fidelidade". Guiomar Torrezão narra-nos igualmente o bulício cortesão e a vida da sociedade elegante madrilena, que se desdobra em tertúlias, bailes e serões. Nos quinze dias que passa em Madrid, Guiomar Torrezão entrega-se encantada a esta intensa vida social, e narra-nos eventos como o Baile do Paço, a visita ao Congresso, o jantar literário promovido pela Princesa Ratazzi em sua honra ou o batizado da filha de D. Luiz de Rute e da sua esposa, que teria como madrinha a rainha-mãe, Isabel II e como padrinho 
Emilio Castelar. Partilha com o público leitor descrições minuciosas do interior do Palácio Real e da casa dos seus anfitriões. Taurófila, não deixa de assistir a uma corrida de touros, tal como acontece com a maioria dos viajantes portugueses e de visitar o Museu do Prado.

\section{0 Espaço ficcionado}

A visita a Madrid a pretexto da cobertura jornalística para o Diario Ilustrado do casamento real não esconde, porém, os verdadeiros ensejos desta estada que tem como destino último Paris. Na verdade, este périplo prende-se muito mais com motivos literários do que propriamente jornalísticos, uma vez que Guiomar Torrezão aproveita a o casião para travar conhecimento e aprofundar relações com algumas das personalidades artístico literárias mais relevantes de Espanha e de França.

0 facto de se hospedar no Palácio Montalban não é, de facto, inocente. Guiomar Torrezão manterá com a aristocrata francesa uma ligação conhecida, que se consolidaria com a publicação das suas notas biográficas no Almanach das Senhoras ${ }^{10}$, ou com a tradução da sua obra em Portugal, nomeadamente do seu livro Ratazzi e o seu tempo ${ }^{11}$ e do polémico Portugal de Relance ${ }^{12}$. A tradução da obra, que inflamará as opiniões lusas, embora não se encontre assinada e apenas refira ter sido "auctorisada pela autora", parece ser claramente atribuível a Guiomar Torrezão, de acordo com Monteiro Ramalho que detratou o livros e a sua autora, em As ratices da Ratazzi ${ }^{13}$. 0 livro seria acerbamente criticado por alguns dos mais notáveis escritores portugueses, entre eles Camilo Castelo Branco.

A amizade pessoal, mas também razões profissionais, ligavam, por conseguinte, as duas mulheres, sendo mesmo possível encontrar cópias de exemplares da narrativa de Guiomar Torrezão Paris, Impressões de viagem, anotadas pela própria Princesa. Era pois lógico que, na sua estada em Madrid, acompanhada pela sua mãe, Guiomar Torrezão se hospedasse na casa de Maria Ratazzi.

A pequena narrativa de viagens a Madrid, onde convida o leitor a percorrer as ruas da capital madrilena, acompanhando-a igualmente numa visita pelo Madrid literário e pelo Madrid mundano, nos numerosos eventos a que assiste, é uma obra de cunho memorialístico e autobiográfico, mas que tem também um certo pendor publicista. De facto, 
as suas observações e a rigorosa descrição do trabalho da Princesa Ratazzi e do seu gabinete, onde, sob o pseudónimo de Baron Stock, dirigia a publicação Matinées espagnoles $^{14}$, parecem-nos não só um elogio à inteligência e à atividade literária da Princesa, mas essencialmente uma prova de como as mulheres, devidamente educadas, não devem ser menosprezadas, cotejando a situação portuguesa com a espanhola.

Guiomar Torrezão manifesta uma verdadeira admiração pela Princesa, talvez por ser o exemplo da mulher que ela tão propaladamente defendeu nos periódicos oitocentistas, o de uma mulher letrada, instruída, mas sempre usufruindo de uma vida doméstica ou então mundana, pautada por uma moral algo "austera". Veja-se a descrição do quotidiano da Princesa:

Madame de Rute recebia em Madrid aos sábados de manhã, quasi sempre com o atractivo de uma recitasinha, oferecida ás juvenis amigas de Izabel Roma, e recebia aos domingos, de quinze em quinze dias, os amigos e colegas do barão Stock. Antes e depois das recepções frequentava assiduamente as Cortes, o Retiro, os theatros e bailes, abandonava-se sem restrições à voragem que se chama a alta vida. Pois apesar d'isso, a ilustre jornalista achava sempre o tempo indispensável para trabalhar hora seguidas, com o olhar de myope preso à sua grande escrivaninha, entre montanhas de jornaes e correspondências que lhe chegavam a cada instante das cinco partes do globo, com a mesma aplicação e a mesma tenacidade com que eu trabalho no isolamento de meu pobre quarto, forçada pelos deveres inherentes à minha profissão. (Torrezão 1898: 68-69)

Parece-nos que, no caso específico da Princesa Ratazzi, Guiomar Torrezão vai mais longe do que apenas na maioria dos casos, quando elogia as mulheres intelectuais do seu tempo, como George Sand, Sarah Bernardt ou as portuguesas Maria Amália Vaz de Carvalho, entre outras. De facto, a escritora portuguesa, que não perde ocasião para denunciar a menorização a que estavam sujeitas as mulheres de letras no nosso país, pugnando por uma melhor educação feminina, vota grande parte da sua obra ao elogio e à valorização destas mulheres, embora não as ofereça como modelo a seguir (Outeirinho 1999).

Para além da Princesa Ratazzi, ícone desta mulher intelectual, mas votada aos deveres domésticos, que Guiomar Torrezão publicitava, outra figura das letras espanholas que a autora nos apresenta é Emilia Pardo Bazán. A escritora de origem galega, mas que 
seria uma madrilena de coração e alma, é descrita como uma "polyglota que tem percorrido quasi toda a Europa e escreve com a erudição de um sabio e a fina sensibilidade de uma mulher."

Por estar muito consciente de que a sensibilidade e o gosto femininos são bem diferentes, os temários que aborda na sua narrativa de viagens são um conjunto de topoi já consagrados pela Literatura do género, com uma focalização feminina, dando maior destaque a observações como a descrição dos pormenores de interiores, ou a opulência d as toilettes femininas:

Havia três dias que a elite da villa Coronada não pensava senão nesse baile, que se annunciara prodigo em seducções e attractivos. A toilette com as suas mil e uma exigências tornara-se a preocupação dominante. (Torrezão 1898: 32)

\section{Conclusão}

A narrativa de viagens de Guiomar Torrezão apresenta-nos uma perceção do espaço vivido submetida ao paradigma de uma visão feminina, num tom de crónica social, destinado sobretudo ao gosto do público feminino. Daí que se multipliquem os pormenores relativos aos vestidos e fatos usados, às joias, à decoração dos espaços interiores e até pequenas boutades muito ao gosto feminino, como o da idade da Duquesa de la Torre. Conta-nos Guiomar Torrezão, que no teatro observando a duquesa, "no momento em que o meu binoculo fixava essa cabeça de estatua, o barão de Stock curvou-se e disse-me ao ouvido a edade da duquesa. O binoculo caiu-me das mãos. Oh! Magico poder da tinta, artisticamente usada!..."

No entanto, não nos parece despicienda, no caso específico do livro de Guio mar Torrezão, num contexto finissecular, a reflexão sobre as fontes a que a autora lança mão. Se a maioria dos livros de viagem portugueses que nos ocuparam tem nos autores franceses da primeira metade do século a sua fonte de inspiração primordial, a narrativa de Guiomar Torrezão, muito embora não renegue completamente essa tradição gaulesa, par ece relegála para segundo plano. Há de facto passagens que nos lembram descrições de outros escritores portugueses que se deslocaram a Espanha. Parece mesmo que Guiomar Torrezão 
escreve com os olhos postos nesses livros. A título de exemplo, citamos a sua descrição da mulher espanhola que, pela oposição que estabelece entre um ponto de vista "plástico" e o ponto de vista "esthetico", lembra ostensivamente a descrição que Ramalho Ortigão tinha feito das espanholas, alguns anos antes (ortigão 1949).

Finalmente, o espaço ficcionado, a Espanha do cliché literário, das memórias partilhadas pelo viajante e pelo público leitor, não é descurado pela atenção de Guiomar Torrezão. A Espanha lendária, do exotismo e do pitoresco românticos, é também ela motivo de apreço:

Fallarei ainda um pouco dessa Hespanha que todos nós pensamos que conhecermos, logo que avistamos a serra de Guadarrama, toucada de neve como o Iungfrau, mas que Madrid, como qualquer cidade estranha não pode de maneira alguma fazer-nos conhecer. (Torrezão 1898: 78)

A tese que defende é a mesma que encontramos nos autores que escrevem já mais perto do fim de século. 0 pitoresco já não existe em Madrid e a capital espanhola não passa de uma "sucursal de Paris". Guiomar Torresão explica onde reside a cópia: Madrid "começou por eliminar a mantilha e acabou pintando-se de loiro". Tal como outros autores de finais de Oitocentos, também Guiomar Torrezão vincula a ideia arreigada de que o pitoresco espanhol reside apenas na Andaluzia. "A Hespanha - defende - com a sua música fascinadora, os seus trajes pitorescos, a sua physionomia característica, concentrou -se toda na Andaluzia, Granada e Sevilha." Em Madrid, os únicos traços deste exotismo e do carácter espanhol estão reduzidos a dois espaços, conclui a viajante, aos ca fés e aos touros.

As imagens estereotipadas da Espanha resultam, como se pode concluir, de uma súmula de descrições vivazes, fixadas pelos viajantes. Garcia-Romeral descreve, desta forma, a construção de uma imagem sobre o espaço visitado. Esta “cor local”- que poderíamos também conformar à expressão do inglês Richard Ford "coisas de Espanha"constitui, na sua essência, um conjunto de imagens fixas, persistentes e pertinazes que os viajantes de diversos horizontes geográficos reproduziriam. Eram, na verdade, os motivos que levavam os viajantes a Espanha, que eles esperavam reconhecer e redescobrir.

Os viajantes portugueses não são exceção a este fenómeno e encontramos nas suas 
descrições, mormente no caso específico de Guiomar Torrezão, os mesmos topoi que outros escritores consagrados exploraram. Estes tópicos são eles próprios frequentemente comentados pelos viajantes que, ora lamentam o desaparecimento do pitoresco característico espanhol, ora exclamam "quem, nas viagens, buscar o pitoresco, venha à Hespanha, que é talvez o último recan to da Europa onde a vida antiga, por fora e por dentro, se conserva intacta" (Martins 1893:127).

Guiomar Torrezão manifesta um particular apreço pela Espanha dos ambientes históricos mitificados, das paisagens pitorescas, do colorido exótico dos costumes e tradições. Viajar pelo mundo converte-se num fim em si mesmo, uma vez que a viagem contribui para cultivar a sensibilidade e exaltar a emoção da alma. Viajar é poder sentir a emoção da aventura diante de situações desconhecidas e imprevistas. Mas é igualmente uma forma de desvendar tradições e costumes de outros povos e, logo, conhecer a identidade histórica dos países visitados. Ora, a partir de meados da década de 70 do século XIX, encontramos uma atitude mas que se propagaria aos restantes viajantes, que designaríamos por "decadentista”. Os viajantes, Guiomar Torrezão incluída, já não encontram essa imagem sonhada e ficcionalizada da Espanha romântica, e o seu lamento pela decadência em que descobrem o país. De facto, o desenvolvimento industrial, o crescimento das cidades e a explosão demográfica diluiria muitas das tradições e da etnografia que os românticos tanto apreciavam. O desenvolvimento dos meios de transportes acabaria com o perigo e a aventura do trajeto. A viagem deixara de ser uma aventura existencial que oferecia emoção e entusiamo. Guiomar Torrezão denuncia a vulgarização da imagem da Espanha, de onde desapareceu o pitoresco para dar lugar à homogeneização e à imitação das sociedades mais desenvolvidas do Norte. Instala-se, finalmente, a profunda crise de valores que caracterizaria a atitude desta elite finissecular, que simultaneamente se verteria numa profunda reflexão sobre a identidade nacional. 


\section{NOTAS}

1 Veja-se, por exemplo, a comparação que Ramalho Ortigão faz entre a França e a Península Ibérica numa das suas Farpas: "O séc. XVIII, em Portugal tão lugubremente tenebroso de embiocamento beato, de crasso mau gosto, de nojenta hipocrisia, foi em França dos de mais brilho para a história do talento e das artes. Da própria regência, com toda a devassidão, diz Michelet, que através de todos os vícios e de todos os erros, ela tinha esta particularidade benéfica e simpática: - era do partido do futuro. 0 inimigo era o passado, era a Espanha representante da Idade Média, a Espanha, abrasada em fogueiras, a Espanha que, vitoriosa, retardaria 100 anos a marcha da humanidade, porque teria queimado Montesquieu e Voltaire." (Queirós, Ortigão, 2004: 216)

20 artigo "Spaniards" de José Manuel López de Abiada explora as noções hispanofobia e hispanofilia (Lopez de Abiada, 2007).

3 “(...) Passam-me no espírito mil ideias que se combatem, umas a fallarem-me de feudalismo, de inquisição, de fanatismo, outras de castanholas, de pandeiros, de cachuchas, de serenatas, de costumes poéticos e pittorescos" (Machado, 1965:20).

4 Veja-se o prólogo de Pierre Brunel em Moureau, 1986 :7-13.

5 Também Manfred Beller afirma: “(...) when people from various countries and cultures meet each other, real experience and mental images compete. Earlier meetings with others shape our pre-expectations - which in turn predetermine further meetings with other Others. It is not possible to distinguish what, in our attitudes, is primordial, pure experience, and what derives from the culturally accumulated images. There is no such thing as a pristine encounter. Our attitudes are culturally determined, as ethologists have tried to explain by means of analogies of how animals and humans relate. Cognitive psychology calls this "selective attention". Literary texts also reduce the complex of various characteristics of an individual to a small number of noteworthy, salient aspects and characteristics. With collective, which we assume into one concept, as groups, peoples or races, these emerge in the formulaic of stereotypes." (Beller e Larssen, 2007: 7).

${ }^{6}$ Os estudos imagológicos cedo mediram a importância das auto-imagens e das hetero-imagens na construção da identidade nacional e abordaram a Literatura de viagens como fonte inesgotável dessa construção: “(...) A dimensão do Estrangeiro sempre presente numa cultura nacional passa por práticas discursivas várias e concorrentes em que a dilucidação da suposta singularidade de um povo decorre do hábito, já vetusto, de congregar e eleger traços identificadores do Outro, tendo lugar, com frequência, uma perpetuação tras-secular de imagens estereotipadas. Tais práticas decorrem da existência de um eu que olha o outro, necessariamente a partir de si, e que, ao falar do outro, se implica em construções de alteridade, mas também em construções de identidade, mesmo quando a tomada de consciência de tal processo não tem lugar." (Outeirinho, 2003: 1). 
7 Para ler mais sobre estas autoras, consulte-se Ana Maria Costa Lopes (2005), Imagens da Mulher na Imprensa Feminina de Oitocentos, Percursos de Modernidade, Lisboa, Quimera Editores e Zilda Osório de Castro e João Esteves (2005), Dicionário no Feminino (séculos XIX-XX), Lisboa, Livros Horizonte.

${ }^{8}$ Sobre estas questões consulte-se OUTEIRINHO, 2003 sobretudo o capítulo "A mulher no folhetim", pp. 226381.

${ }^{9}$ Fialho d'Almeida, “Guiomar Torrezão", Almanach das Senhoras para 1900, Lisboa, Parceria Antonio Maria Pereira, 1899, p. 8.

10 Torrezão, 1870.

11 Rattazi, 1881.

12 Ratazzi, 1881.

13 Ramalho, 1880, Branco, 1886.

14 Sobre a publicação, escreve Guiomar Torrezão: “É alli que se escrevem as Matinées espagnoles, é alli que se exerce a febril actividade d'essa organização fenomenal, que tem passado através da Europa, maravilhando-a com a publicação dos seus livros e jornaes, com o escândalo das suas aventuras, polychromia oftálmica das suas toilettes, com a kermesse das suas salas e onde se reúnem os incompatíveis e confraternizam os dissidentes, com a opulência discutida pelos incrédulos das suas jóias" (Torrezão 1898: 68). 


\section{Bibliografia}

Almeida, Fialho (1890), Pasquinadas: jornal d'um vagabundo, Porto, Livraria Chardron.

Beller, Manfred e Leerssen, Joep (org.) (2007) Imagology. The cultural construction and literary representation of national characters. A critical survey, Amsterdam, Rodopi.

Brunel, Pierre (1986) Prefácio a "Métamorphoses du récit de voyages", in Actes du Colloque de la Sorbonne et du Sénat, Paris, Champion et Genève, Slatkine.

Castro, Zilda Osório de, Esteves, João (2005), Dicionário no Feminino (séculos XIX-XX), Lisboa, Livros Horizonte.

Clément, Vincent (1998), "La perception romantique de la Castille à travers le récit de voyage de Téophile Gautier », L’Espace Géographique, nํ4, pp. 359-366.

Fernández Herr, Elena (1973), Les origines de l'Espagne romantique. Les récits de voyage 1755-1823, Paris, Didier, p. 21.

Foulché-Delbosc, Raymond (1991) Bibliographie des voyages en Espagne et en Portugal, (1896), Madrid, Julio Ollero editor.

Lopez de Abiada, José Manuel (2007), “Spaniards”, in Beller, Manfred e Leerssen, Joep (org.) (2007) Imagology. The cultural construction and literary representation of national characters. A critical survey, Amsterdam, Rodopi, pp. 242-247.

Lopes, Ana Maria Costa (2005), Imagens da Mulher na Imprensa Feminina de Oitocentos, Percursos de Modernidade, Lisboa, Quimera Editores.

Machado, Júlio César (1865), Em Hespanha. Scenas de Viagem, Lisboa, Livraria de A.M. Pereira.

Martins, J.P. Oliveira, (1893) A Inglaterra de Hoje: cartas de um viajante, Lisboa, Livraria A. M. Pereira.

Montalbetti, Christine (1998), « Entre écriture du monde et réécriture de la bibliothèque:

N. ${ }^{\circ} 38-6 / 2018$ | 271-293 - ISSN 2183-2242 | http:/dx.doi.org/10.21747/21832242/litcomp38a15 
conflit de la référence et de l'intertextualité dans le récit de voyage au XIX ${ }^{\text {e }}$ siècle », dans Sophie Linon-Chipon, Véronique Magri-Mourgues et Sarga Moussa (éds.), Miroirs de textes. Récits de voyages et intertextualité, Nice, Publications de la Faculté des Lettres, Arts et Sciences humaines de Nice (Nouvelle série, ${ }^{\circ}$ 49), pp. 3-16.

Moureau François (dir.) (1986) Métamorphoses du récit de voyage. Actes du Colloque de la Sorbonne et du Sénat, Genève, Slatkine.

Ortigão; José Duarte de Ramalho (1949), Pela Terra Alheia, 2 vols. Lisboa, Livraria Clássica Editora. (1ํa* edição 1878).

-- (1943), Em Paris, Lisboa, Livraria Clássica Editora.

-- (1942-46), As Farpas (Edição Integral), com um estudo de Augusto de Castro, 15 vols., Lisboa, Livraria Clássica Editora.

-- (1945), “Carta a D. Guiomar Torrezão” in Figuras e Questões Literárias, Tomo II - Perfis de Escritores e Problemas de Estilo, Lisboa, Livraria Clássica Editora, pp. 7-19.

-- (1946), Farpas Esquecidas, 2 vols, Lisboa, Livraria Clássica Editora

Outeirinho, Maria de Fátima (1997), À distância de mais de meio século: Paris em Ramalho Ortigão e Abel Salazar, sep. Intercâmbio, nํㅛ, Porto.

-- (2000), “Representação do Outro e Identidade: Um Estudo de Imagens na Narrativa de Viagem. II - Um estudo de caso: a narrativa de viagem oitocentista", in Cadernos de Literatura Comparada - Para uma crítica do discurso crítico. Narrativa Literária e Identidade, Instituto de Literatura Comparada Margarida Losa, Porto, Granito Editores e Livreiros.

-- (2002), A Viagem a Espanha. Em torno de alguns relatos de viagem oitocentistas, sep. da Revista da Faculdade de Letras do Porto. Línguas e Literaturas.

-- (2003a), O Folhetim em Portugal no Século XIX: uma nova janela no mundo das letras, dissertação de doutoramento apresentada à Faculdade de Letras da Universidade do Porto, especialmente “A crónica de viagem”, pp.166-209.

N. ${ }^{\circ} 38-6 / 2018$ | 271-293- ISSN 2183-2242 | http:/dx.doi.org/10.21747/21832242/litcomp38a15 
-- (2003b), "Representações do Outro na narrativa de viagem oitocentista", Cadernos de Literatura Comparada 8/9:Literatura e identidades, Orgs. Ana Luísa Amaral, Gonçalo VilasBoas, Marinela Freitas, Rosa Maria Martelo, Porto: Instituto de Literatura Comparada Margarida Losa, 2003, pp. 67-76.

Pageux, Daniel-Henri(1994) La Littérature générale et comparée. Paris: Armand Colin.

Ratazzi, Marie (1879) Le Portugal à vol d'oiseau. Portugais et Portugaises, Paris. A. DegorceCadot.

-- (1881), Portugal de relance, tradução portugueza (auctorizada pela autora), Lisboa, Livraraia Zeferino editora.

-- (1881) Ratazzi e a sua época, trad. de Guiomar Torrezão, Lisboa, Oficina typographica de J.A. Matos.

Soja, Edward (1996), Thirdspace: Journey to Los Angeles and other real-and-imagined places, Oxford, Blackwell.

-- (1989) Postmodern Geographies. The Reassertion of Space in Critical Social Theory, London/New York.

Torrezão, Guiomar (1898) A toda a velocidade. Notas de gare, Porto, Livraria Portuense. 
Sara Pascoal is a Professor at the Polytechnic Institute of Porto (P.Porto - ISCAP), Portugal, since 1997. She has an undergraduate degree in Modern Languages and Literatures, a Master's degree in Portuguese Culture and a PHD in Romanic Languages and Cultures. She is currently doing research on Literary geography and Literary to urism and she's involved in the SAICT/ FCT Project "TheRoute - Tourism and Heritage Routes including Ambient Intelligence with Visitants' Profile Adaptation and Context Awareness". Her PHD thesis, entitled "Pela Espanha Alheia: espaços vividos, espaços ficcionados" lies at the crossroads of Intercultural studies, Comparative Literature and Geography of Perception. She is a researcher and member of the Scientific Board of the Centre for Intercultural Studies of IPP; a researcher at the Institute for the Study of Literature and Tradition (IELT) of the Universidade Nova de Lisboa, and Vice-Director of the Master's Degrees in Specialized Translation and Interpreting and in Intercultural Studies for Business, at IPP. She is the Director of the new Bachelor Degree in Language Management for International Business. Her research interests range from Geocriticism, Visual Rhetoric to Semiotics to Intercultural Communication, Portuguese Culture and Translation.

N. 38 - 6/ 2018 | 271-293 - ISSN 2183-2242 | http:/dx.doi.org/10.21747/21832242/litcomp38a15 